\title{
MULTI-OMICS OF GENUS SOLANUM L. TRICHOMES REVEALS THE INTERSECTION BETWEEN STRESS MEMORY AND THE MOLECULAR PATHWAYS FOR RECOVERY
}

\author{
Ewas, Mohamed ${ }^{1 *}$ and Omran Ghaly ${ }^{2}$ \\ ${ }^{1}$ Deptment of Plant Genetic Resources, Desert Research Center, Cairo, \\ Egypt \\ ${ }^{2}$ Department of Plant Ecology and Range Management, Desert \\ Research Center, Cairo, Egypt \\ *E-mail: Mohamed82@webmail.hzau.edu.cn \\ Mohamed_ewas82@yahoo.com
}

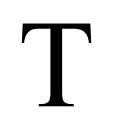

richomes are cosmopolitan biological textures originating from the aerial epidermis, which render as a superior model to investigate plant differentiation at the cell level. The main function of these epidermal protuberances is protection from abiotic and biotic stresses. Trichomes are classified to glandular and non-glandular types. Glandular trichomes are biochemical factories and storage compartments for a diverse array of specialized metabolites. However, little knowledge is available about the plant machinery to coordinate trichome formation, metabolism regulation, and stress resistance. In the present study, trichomes are proved to be the key link between stress memory and the molecular mechanism of Solanaceous species for recovery. Scanning with electron microscope "SEM" confirmed the distribution of four glandular and six non-glandular trichome types between the studied Solanum species. Multi-omics analysis including genomic, transcriptomic, and metabolomic studies revealed that Solanum species, which contain approximately equal density and same types of trichomes are closer genetically to each other. Several stress-responsive cis-elements were identified through in-silico analysis of the promoters of MIXTA, MIXTAlike1 and MIXTA-like2 the key genes of trichome formation. The transcriptomic results demonstrated that all genes were differentially expressed in the studied Solanum species due to trichome types and density according to its tolerance to stresses.

The $1^{\text {st }}$ Scientific Conference of Plant Genetic Resources Department, Ecology and Dry Lands Agriculture Division, Desert Research Center "Plant Genetic Resources and Sustainable Development Under Egyptian Desert Conditions" 13-16 November, 2019, Sharm El-Sheikh, South Sinai, Egypt 
This report shed light into endemism of Solanum species in their defined zones.

Keywords: trichomes, environmental challenges, stress memory, molecular pathways, MIXTA transcription factors, endemism, Solanum species

Trichomes are cosmopolitan biological textures originating from the surfaces of the leaf and stem, which render as a superior model to investigate plant differentiation at the cell level (Yang et al., 2011). Generally, these epidermal structures can be classified into glandular or non-glandular trichomes (Kim et al., 2012). These epidermal outgrowths have generally been considered as agro-trait of little worth, due to its negative sides including the lower preference of farmers and the causing factor for allergy. However, the trichomes have proved to be directly or indirectly involved in the plant protection from drought (Ewas et al., 2016), high salinity (Skaltsa et al., 1994), ultraviolet radiation (Espigares and Peco, 1995), high temperature (Thomas et al., 1992), cold (Dhawan et al., 2016), herbivores, and pathogen attacks (Ewas et al., 2017) along with heavy metals (Ager et al., 2003). Epidermal outgrowths of plants have various complex forms and functions, which can be present individually or in combination on surface of the same plant (Glover and Martin, 2000). The microscopic characteristics of trichomes are important tools in comparative systematics to shed light into the evolutionary relationships between and within plant species (Theobald et al., 1979). Plants frequently are covered with different types of trichomes that vary among species. Taxonomic characters of specific trichome types have been scrutinized in various plant species, in particular blossoming plants such as snapdragon (Dudareva et al., 2005), eggplant (Solanum melongena) (Frary et al., 2003), potato (Solanum tuberosum) (Plaisted et al., 1992), tomato (Solanum lycopersicum) (Levin, 1973 and Ewas et al., 2017), and Arabidopsis (Valverde et al., 2004).

Sundry different types of trichomes are present on the surface of hypocotyls, leaves, stems, floral organs, and fruits of a single tomato plant (Solanum lycopersicum) (Kang et al., 2010). Taxonomic survey of Solanum lycopersicum identified four morphologically distinguished glandular trichomes: type I trichomes described by a multicellular base and a tall multicellular stalk $(\sim 2 \mathrm{~mm})$ with a small glandular end; shorter IV type $(\sim 0.3 \mathrm{~mm})$ that have a unicellular base, shorter multi-cellular stalk than type I trichomes with a tiny glandular tip; type VI consisting of four-celled glandular tip above short multi-cellular stalk $(\sim 0.1 \mathrm{~mm})$; and type VII trichomes containing an irregularly shaped 4 to 8 cell gland on a short unicellular stalk $(<0.05 \mathrm{~mm})$. Both of types II and III are identical in length approximately $(0.2-1.0 \mathrm{~mm})$, but vary in multicellular and unicellular base presence, respectively, while type $\mathrm{V}$ trichomes characterized by a unicellular base shorter stalk $(0.1-0.3 \mathrm{~mm})$

Egyptian J. Desert Res., 69, Special Issue, 69-90 (2019) 
(Luckwill, 1943). There is a vast diversity of trichome customs and chemical makeup inside Solanum species (Schilmiller et al., 2008).

The genus Solanum is one of the most important economic value genera among the Angiosperms, while a few studies were offered in crop genetics and molecular biology (Oh et al., 2008; Yoon et al., 2008; Kim et al., 2010 and Yeom et al., 2011). Due to the association of diverse stress resistances with trichome-forming phenotype, molecular investigations were carried out on trichome-formation in pepper and tomato (Kim et al., 2011; Kim et al., 2012; Ewas et al., 2016 and 2017). R2R3 genes that encoding the MIXTA-like MYB transcription factors are responsible for establishing the conical cells in the petals of Angiosperms (Noda et al., 1994) and are distinctly possible responsible for regulating trichome formation in different species (Gilding and Marks, 2010). These pursuits involve biochemical functions in organizing cuticle formation (Oshima et al., 2013), which impact responses to various environmental stresses (Gilding and Marks, 2010). Association of trichome formation and density with resistance to tomato mosaic virus (TMV) (Ewas et al., 2017) and pepper mottle virus (PepMoV) (Kim et al., 2011) was examined. However, the classification of trichome development due to environmental stresses was not reported in the genus Solanum L. (Kim et al., 2012). In the present study, electron microscope was used to observe trichome types on the epidermal surface of five Solanum species grown under normal and drought stress conditions. Also, the expression level of trichomes-key regulatory genes was examined to explore the relationship between plant stress memory and trichome formation.

\section{MATERIALS AND METHODS}

\section{Plant Materials and Growth Conditions}

The present study was carried out on five Solanum species including S. lycopersicum, S. tuberosum, S. melongena, S. nigrum and S. incanum. The taxonomic position and source of the studied species are shown in table (1). All plant species were grown in a greenhouse under a $12 \mathrm{~h} \mathrm{light} / 12 \mathrm{~h}$ dark regime $\left(180 \mathrm{mmol} \mathrm{m}^{-2} \mathrm{~s}^{-1}\right.$ light intensity) with a regulated temperature of between $25-28^{\circ} \mathrm{C}$ (Qian et al., 2015). One-month-old seedlings were used as the non-treatment control, R0, after that all plants were exposed to air-drying at $28^{\circ} \mathrm{C}$ for $80 \mathrm{~min}$ (approximate water loss to $45 \%$; used as the first drought stress treatment, S1) and then all plants were well re-watered for one day (as the first re-watering treatment, R1). Then, half of the R1 plants were grown under normal condition (as the no-stress memory treatment control, C). Two or three cycles of drought and re-watering treatments were applied to improve the stress memory. 
Table (1). The taxonomic position of the studied species according to D'Arcy (1972, 1991) as well as its distribution in Egypt.

\begin{tabular}{|c|c|c|}
\hline Species & Plant material & Source \\
\hline $\begin{array}{l}\text { S. incanum L. (=Solanum bojeri } \\
\text { Dunal, S. sanctum L.) }\end{array}$ & Seeds and leaves & $\begin{array}{c}\text { Gebel Elba and the surrounding mountainous } \\
\text { regions, Egypt }\end{array}$ \\
\hline $\begin{array}{l}\text { S. nigrum L. (=Solanum humile } \\
\text { Lam.) }\end{array}$ & Seeds and leaves & The Nile region including the delta, Egypt \\
\hline S. melongena L. var. esculenta & Seeds & $\begin{array}{l}\text { Vegetable Crops Department, Faculty of } \\
\text { Agriculture, Alexandria University, Egypt }\end{array}$ \\
\hline $\begin{array}{l}\text { S. lycopersicum L. var. Ailsa } \\
\text { Craig (AC) }\end{array}$ & Seeds & $\begin{array}{l}\text { Vegetable Department, Faculty of Horticulture, } \\
\text { Huazhong Agriculture University, China }\end{array}$ \\
\hline $\begin{array}{l}\text { S. tuberosum L. cv. E-potato 3, } \\
\text { (E3) }\end{array}$ & Tubers & $\begin{array}{l}\text { Vegetable Department, Faculty of Horticulture, } \\
\text { Huazhong Agriculture University, China }\end{array}$ \\
\hline
\end{tabular}

\section{FSEM Observation}

The third leaf from the top was collected from the wild species $(S$. nigrum and $S$. incanum) and the two-month-old cultivated species $(S$. lycopersicum, S. tuberosum and S. melongena). Leaves were cut into $\sim 0.1 \mathrm{~cm}^{2}$ pieces then fixed with $2 \%$ glutaraldehyde for roughly $24 \mathrm{~h}$. All samples then were washed in cacodylate buffer $0.1 \mathrm{~mol} / \mathrm{L}$, followed by dehydration in a graded ethanol series, and then dried in a desiccator (HCP-2; Hitachi). The dried samples were coated with a film of gold. Electron microscope model JSM-6390/LV was used for scanning (Yang et al., 2011).

\section{Measurement of Drought-Stress-Related Biochemical Parameters}

Drought-stress-related biochemical markers were analyzed in the studied species after exposing to different drought stress memories and wellwatered treatments. The relative water content was estimated at the four-leaf stage (as drought stress treatment was initiated). Proline and soluble sugars and malondialdehyde (MDA) contents were measured with three replicates according to the previous methods described by Bates et al. (1973) and Orozco and Ryan (1999).

\section{Expression Analyses}

Total RNA was extracted using Trizol reagent (Invitrogen), while the first-strand cDNA was synthesized using $200 \mathrm{U}$ of M-MLV reverse transcriptase (Invitrogen) and $3 \mu \mathrm{g}$ of RNA according to the producer's protocol. Real-time PCR was carried out on an optical 96-well plate using an AB StepOnePlus PCR system (Applied Biosystems) by using SYBR Premix Reagent F-415 (Thermo Scientific). Also, actin gene was used as an internal control, which was amplified with 24 cycles. Gene expression level was 
calculated using a relative quantification method described by Schmittgen and Livak (2008). All primers used in this study are shown in supplemental table (S1).

\section{RESULTS}

\section{Taxonomic Survey of Trichome Types and Density in Five Different Solanum Species}

Field Emission Scanning Electron Microscopy (FESEM) was used for trichomes morphology examination of detached leaves from five well-watered Solanum species: S. lycopersicum, S. tuberosum, S. melongena, S. nigrum and $S$. incanum. FESEM observation recognized 10 distinct types of trichome on the epidermis of leaves and illustrated in detail in table (2) and Fig. (1). Furthermore, SEM revealed that density of glandular and non-glandular trichomes was much higher in the leaves of $S$. nigrum, $S$. incanum and $S$. melongena, respectively, than those in leaves of $S$. lycopersicum and $S$. tuberosum, particularly the trichome type I, that previously described had a small glandular end (Table 2 and Fig. 1). Moreover, all trichome types in $S$. melongena (Fig. 1q, r, s, t, u) and $S$. incanum leaves were shorter than those of S. nigrum, S. lycopersicum and S. tuberosum (Fig. 1v, w, x, y, z).

Table 2. Distribution of trichome types in the leaves of five studied Solanum species.

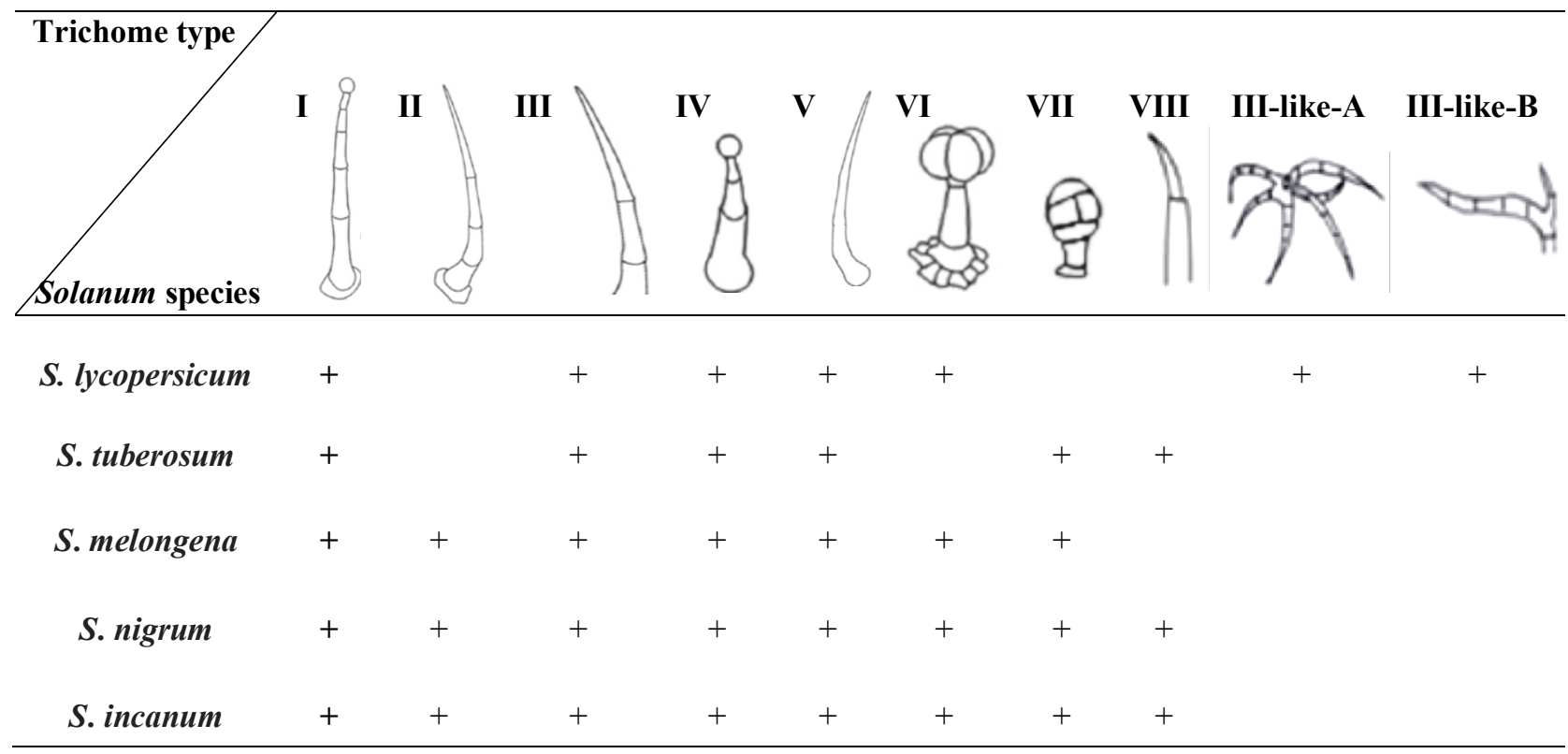

Egyptian J. Desert Res., 69, Special Issue, 69-90 (2019) 


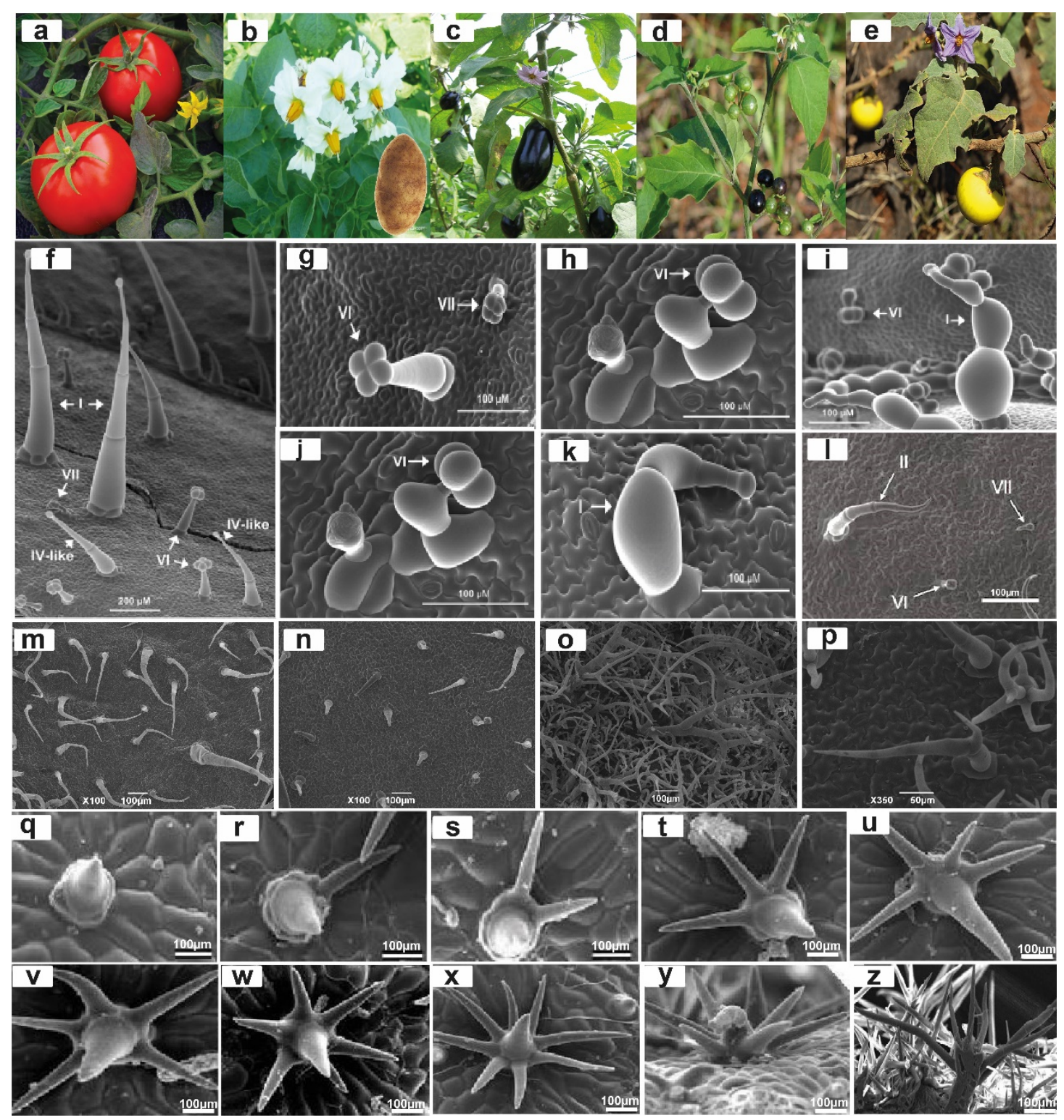

Fig. (1). Initial morphological characterization of investigated Solanum species. Phenotype of (a) Solanum lycopersicum; (b) Solanum tuberosum; (c) Solanum melongena; (d) Solanum nigrum and (e) Solanum incanum. (f-z) trichome types of studied Solanum species including glandular and non-glandular.

Egyptian J. Desert Res., 69, Special Issue, 69-90 (2019) 


\section{Seedlings of Solanum Species Display Drought Stress Memory Under Appropriate Water Deficient Stress}

To explore whether Solanum genus exhibit a drought memory impact, the RWC of the five Solanum species subjected to multiple "drought training treatments" were estimated. The relative water content was reduced as airdrying time prolonged $(0-80 \mathrm{~min})$ for all treatment combinations. No significant differences were recorded in RWC between all stress memories treatments of all Solanum species at 0 min (Fig. 2a, b, c, d, e). The RWC of S1 plants distinctly dropped to $51.54,48.11,60.21,59.71$ and $61.42 \%$ in leaves of S. lycopersicum, S. tuberosum, S. melongena, S. nigrum and S. incanum, respectively, after $80 \mathrm{~min}$ of air drying (Fig. 2a, b, c, d, e). However, the RWC rates of S2-S4 plants were significantly higher than those of S1 plants, and the water content loss was markedly slower after more than two treatments. The significant changes in water loss during cycles of drought treatment indicated that all examined Solanum species showed drought memory after cycles of drought training.

\section{Primary Physiological and Metabolic Parameters are Affected During Drought Memory}

Proline, soluble sugars and MDA have been considered to be critical indicators of drought stress. To confirm the relation between drought stress memory and trichomes formation in Solanum species, proline, MDA and soluble sugars contents were measured after drought stress and re-watered treatments in the leaves of the studied Solanum species. Significant increases in proline values were recorded after drought stress memories S1 up to 2700, 2500, 3200, 3100 and 3500 in leaves of $S$. lycopersicum, S. tuberosum, $S$. melongena, $S$. nigrum and $S$. incanum, respectively. Notably, the increase in proline values of first stress memory S1was much higher than those of S2 and S3 in leaves of all investigated Solanum species, except proline value of $S$. incanum and $S$. nigrum after stress memory S3, which was slightly higher and lower, respectively, than those values after stress memory S1 (Fig. 3a). 


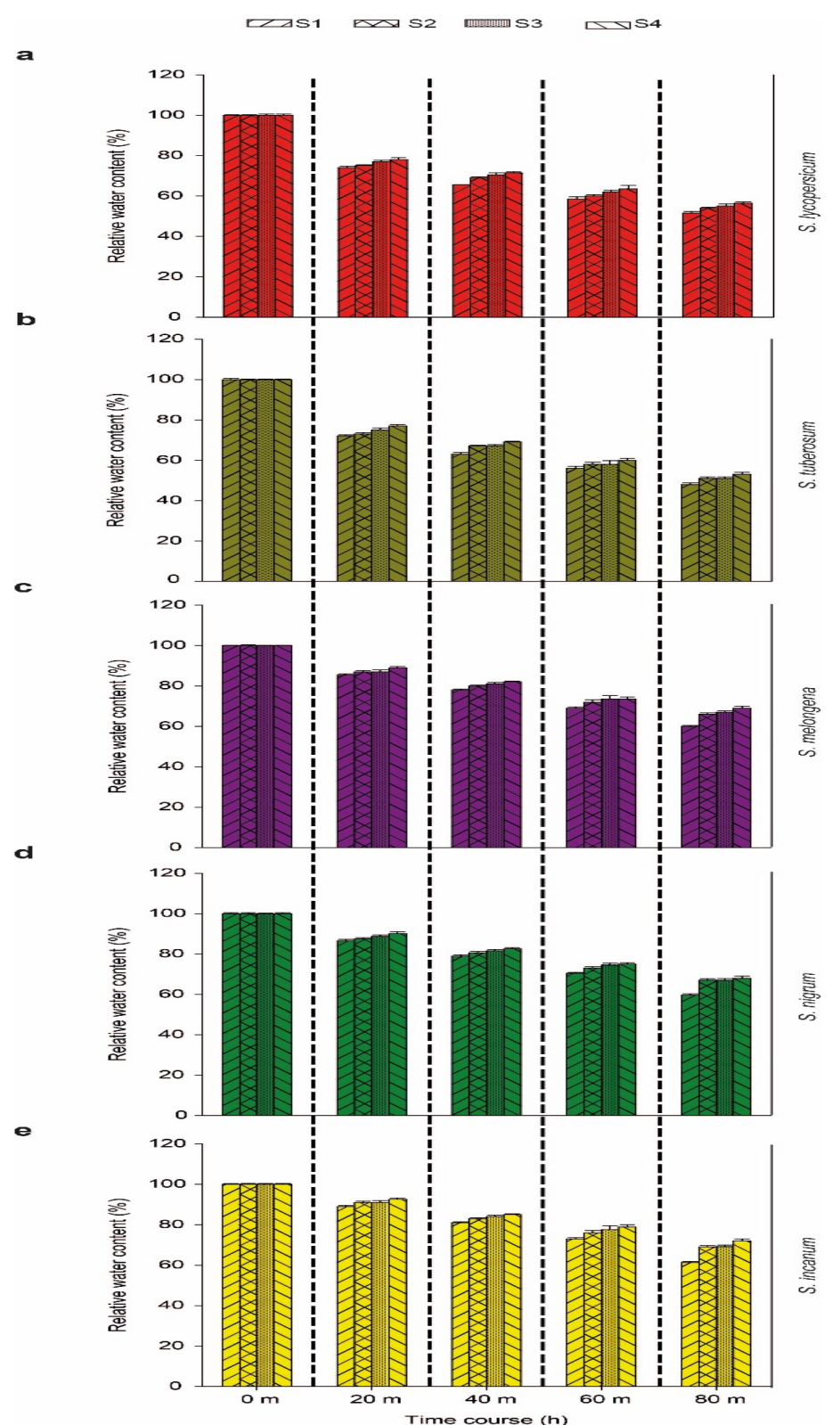

Fig. (2). Plant response parameters during drought training treatment. Relative water content (RWC) of the sampled leaves of Solanum lycopersicum (a); Solanum tuberosum (b); Solanum melongena (c); Solanum nigrum (d) Solanum incanum (e), after air drying for the indicated times. Values are the mean $\pm \mathrm{SD}(\mathrm{n}=8)$.

Egyptian J. Desert Res., 69, Special Issue, 69-90 (2019) 
a

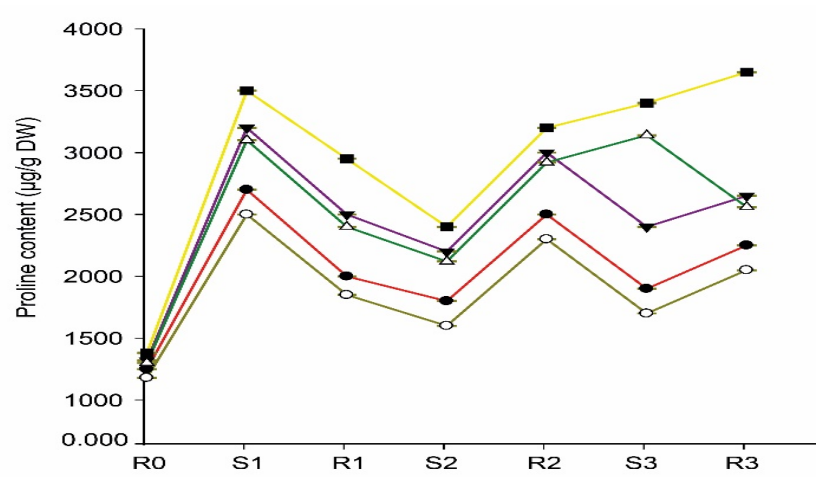

b

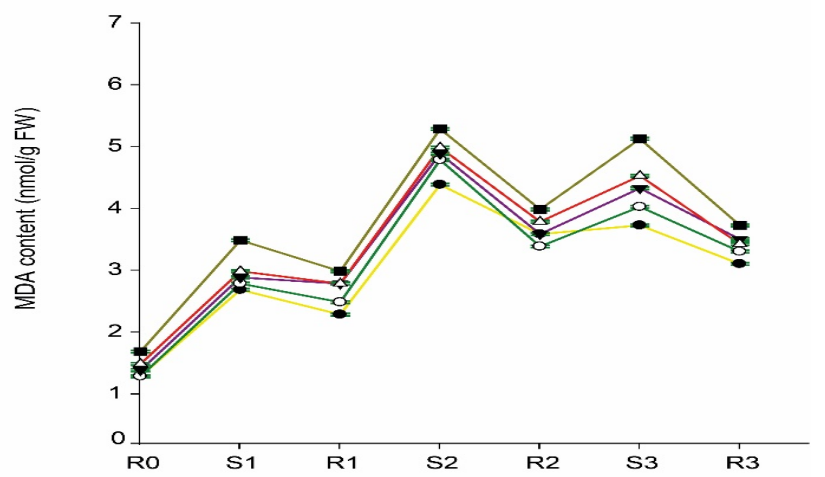

c

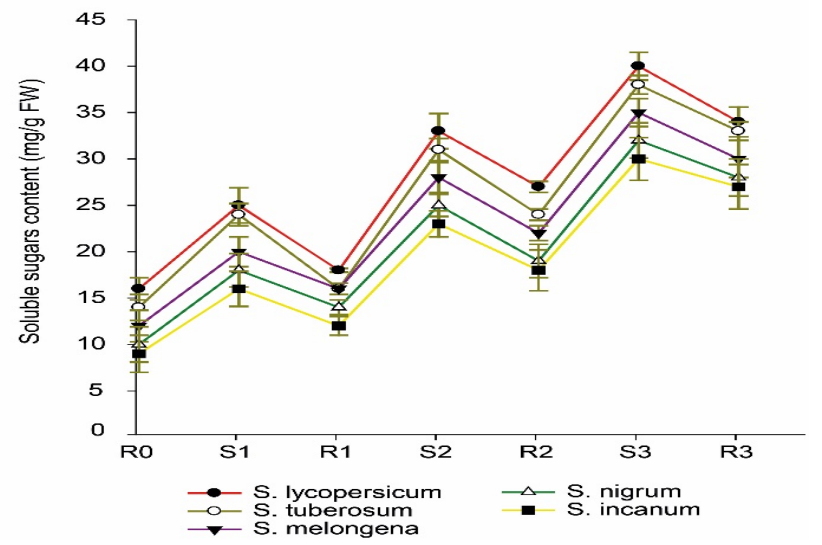

Fig. (3). Plant response parameters during drought training treatment the leaves of investigated Solanum species. (a) Proline content; (b) MDA content and (c) Soluble sugars content. Data are means of three biological and error bars are \pm SE from three independent experiments, each performed with 6-8 leaves from five separate plants.

Egyptian J. Desert Res., 69, Special Issue, 69-90 (2019) 
Interestingly, MDA content was associated with trichome density in the investigated Solanum species, this idea was confirmed by the MDA content results, which showed that MDA values were significantly higher in the leaves of $S$. lycopersicum, $S$. tuberosum and $S$. melongena than those of $S$. incanum and $S$. nigrum after all stress memories.

Surprisingly, the accumulation of MDA after the third drought stress cycle was lower than those of the first and second cycles. On the other hand, a gradual increase in MDA content was correlated with the number of stress memories, especially stress memory S3 of all studied species (Fig. 3b).

Consistent with proline results, a marked increase of soluble sugars content was recorded in leaves of all investigated species after all drought stress memories. The increase in soluble sugars content ranged between 2540, 24-38, 20-35, 18-32 and 16-30 mg/g FW in the leaves of S. lycopersicum, $S$. tuberosum and $S$. melongena, $S$. nigrum and $S$. incanum, respectively, (Fig. 3c).

\section{Genomic Detection of Regulatory Transcription Factors of Trichome Formation in Solanum Species}

Genomic sequences of MIXTA, MIXTA-like1 and MIXTA-like2, the key genes in trichome formation and development were used to design specific primers (forward and reverse) of these genes for detection. The transient analysis indicated the presence of trichome regulatory genes in the genomic DNA of all investigated species including $S$. lycopersicum, $S$. tuberosum and S. melongena, S. nigrum and S. incanum (Fig. 4a, b, c). Notably, the bands of the regulatory genes of trichome formation were obtained at the specific molecular weight that previously reported in different studies.

\section{Transcripts Related to Trichome Formation Could Play Important Functions in Solanum Species Drought Memory}

Many metabolic pathways, in addition to trichomes on the aerial epidermis and hairy roots, play a vital role in plant stress resistance (Ewas et al., 2017 and Li et al., 2019). To explore the cross-link between trichomes and drought stress memory formation in Solanum species, expression level was measured for three transcription factors related to trichome formation after three cycles of drought stress.

SIMIXTA, StMIXTA, SmMIXTA, SnMIXTA and SiMIXTA were assessed in the leaves of $S$. lycopersicum, $S$. tuberosum, $S$. melongena, $S$. nigrum and $S$. incanum, respectively, after three drought stress memories. Water deprivation strongly induced expression level of these genes after first stress memory S1 compared to their transcripts after re-watered R1, while it was slightly expressed after both of stress memories S2 and S3 in comparison with R2 and R3 (Fig. 5a, b, c, d, e). On the other hand, oscillated expression was recorded in the transcription level of SIMIXTA-like1, StMIXTA-like1, SmMIXTA-like1, SnMIXTA-like1 and SiMIXTA-likel, while retaining the

Egyptian J. Desert Res., 69, Special Issue, 69-90 (2019) 
highest gene expression after the first drought stress memory S1 compared to S2 and S3 (Fig. 5f, g, h, i, j).

Interestingly, the expression level of SIMIXTA-like2, StMIXTA-like2, SmMIXTA-like2, SnMIXTA-like2 and SiMIXTA-like2 was gradually increased, especially after dehydration memories $\mathrm{S} 1$ and $\mathrm{S} 2$ (Fig 5k, 1, m, n, o). Furthermore, the bioinformatics analysis of promoter regions for MIXTA, MIXTA-likel and MIXTA-like2 genes also revealed presence of some drought stress-responsive elements such as DRE2-motif, DBF2-motif, MYC-motif, ABRE, MYB-motif, MYC-motif, NAC-motif, bZIP-motif and TC-rich elements (Table 3).

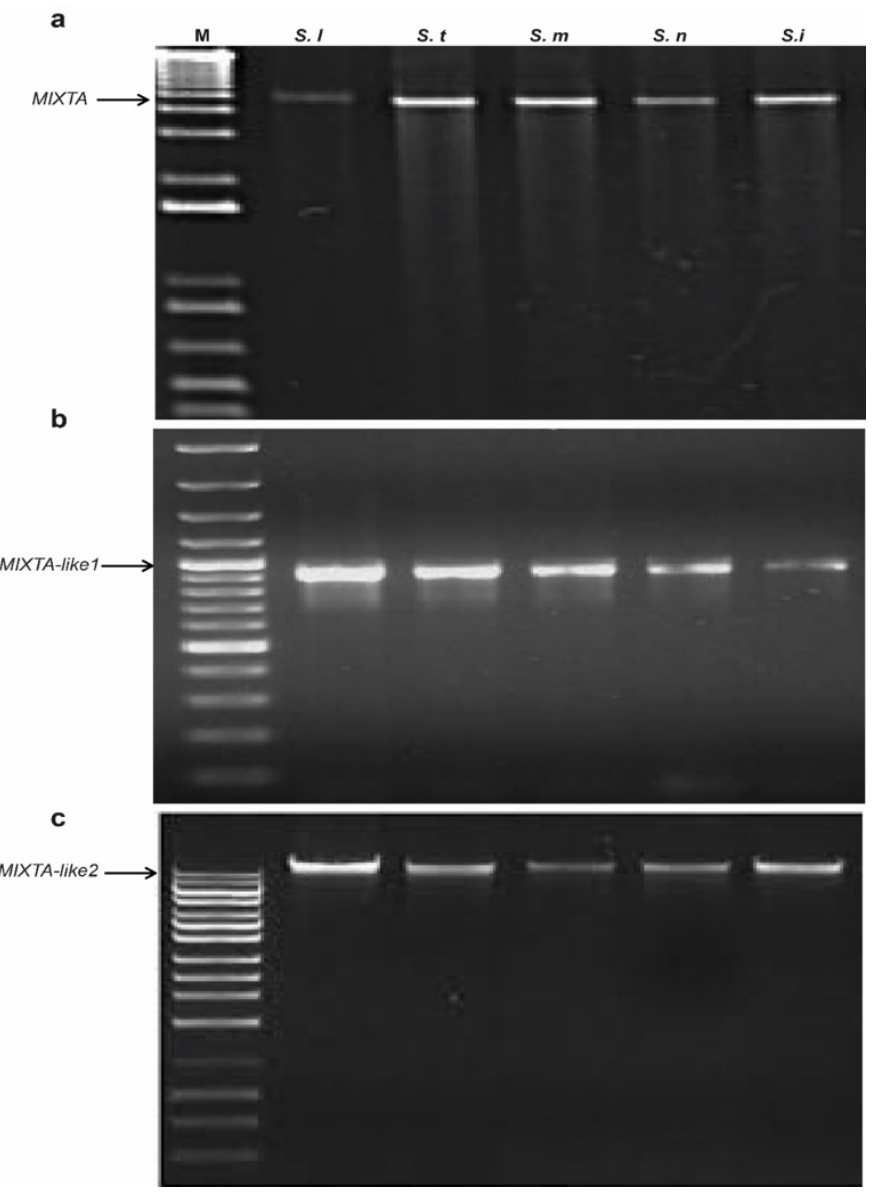

Fig. (4). Genome detection of the key genes involved in trichome formation. MIXTA (a); MIXTA-like1 (b); and MIXTA-like2 (c). DNA was extracted from three biological replicates of each species and detection was carried out using PCR.

Egyptian J. Desert Res., 69, Special Issue, 69-90 (2019) 


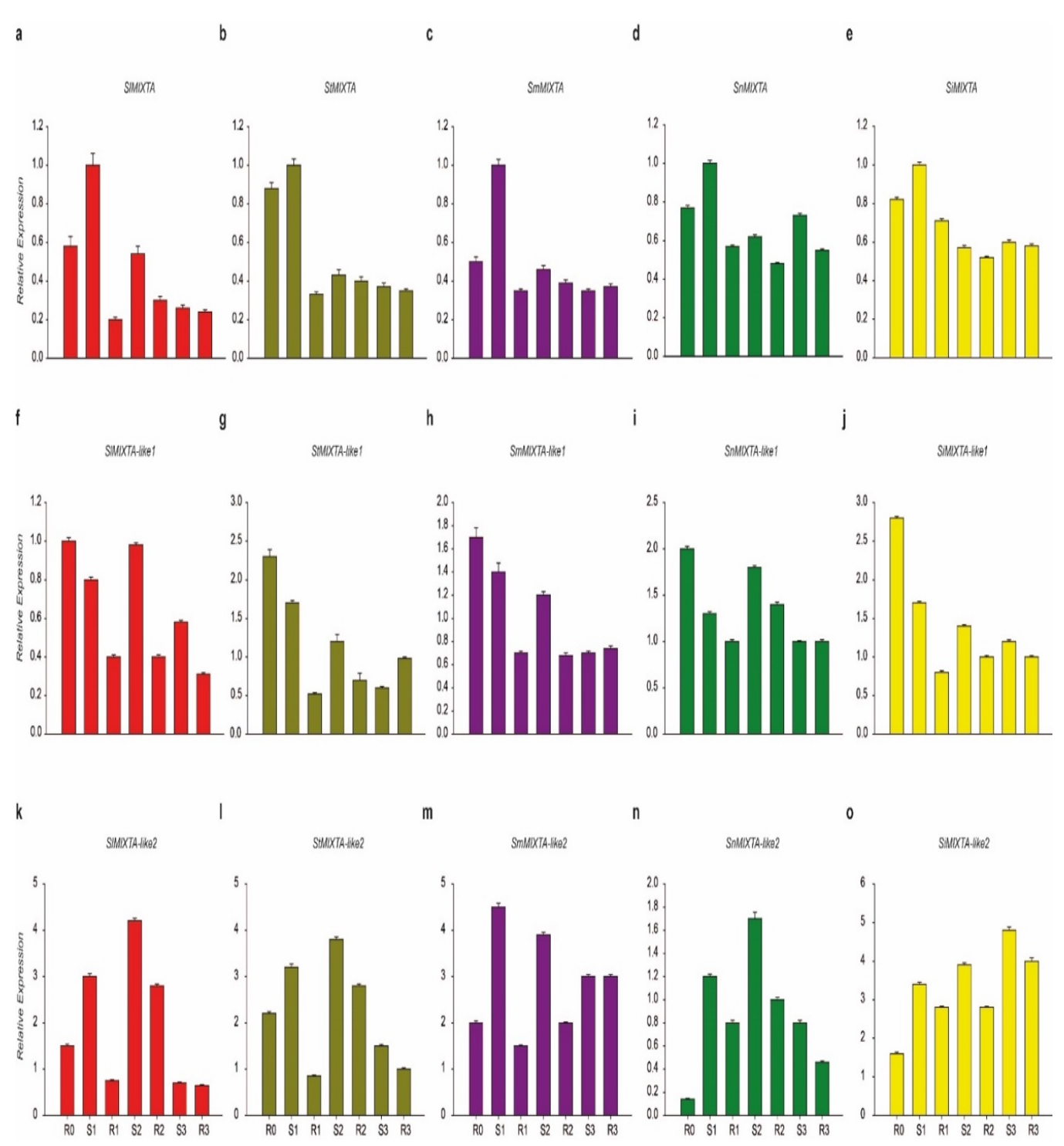

Fig. (5). Real-time quantitative PCR analysis for the transcripts of trichome formation genes involved in stress memory during the drought stress cycles. Actin was used as an internal control. Data are means of three biological replicates and error bars are $\pm \mathrm{SE}$ from three independent experiments, each performed with 6-8 leaves from five separate plants.

Egyptian J. Desert Res., 69, Special Issue, 69-90 (2019) 
Table (3). Cis-regulatory elements responsive to drought stress, salinity stress, osmotic stress and ABA in the promoter regions of MIXTA, MIXTA-likel and MIXTA-like2.

\begin{tabular}{|c|c|c|c|c|}
\hline Pattern & Description & MIXTA & $\begin{array}{l}\text { MIXTA- } \\
\quad \text { like1 }\end{array}$ & $\begin{array}{l}\text { MIXTA- } \\
\quad \text { like2 }\end{array}$ \\
\hline ACGT & $\begin{array}{l}\text { This sequence required for etiolation-induced } \\
\text { expression of erd1. }\end{array}$ & + & + & + \\
\hline ACCGAC & $\begin{array}{l}\text { DBF2" bound to "DRE2"; rab17 is expressed during } \\
\text { late embryogenesis, and is induced by ABA. }\end{array}$ & + & - & + \\
\hline WAACCA & $\begin{array}{l}\text { MYB recognition site found in the promoters of the } \\
\text { dehydration-responsive gene rd } 22 \text {. }\end{array}$ & - & + & - \\
\hline CANNTG & $\begin{array}{l}\text { MYC recognition site found in the promoters of the } \\
\text { dehydration-responsive gene rd } 22 \text { and many other } \\
\text { genes in Arabidopsis. Binding site of ATMYC } 2 \text {. }\end{array}$ & + & + & - \\
\hline ACGTGKC & $\begin{array}{l}\mathrm{DRE} \text { and } \mathrm{ABRE} \text { are interdependent in the ABA- } \\
\text { responsive expression of the rd29A. }\end{array}$ & - & + & + \\
\hline YAACKG & $\begin{array}{l}\text { MYB recognition site found in the promoter of the } \\
\text { dehydration-responsive gene rd } 22 \text {. }\end{array}$ & - & + & - \\
\hline RYACGTGGYR & $\begin{array}{l}\text { ABRE in Arabidopsis dehydration-responsive gene } \\
\text { rd22. }\end{array}$ & & + & \\
\hline CCACGTGG & ABRE; ABA and water-stress responses. & + & + & + \\
\hline YACGTGGC & $\begin{array}{l}\text { ABA responsive element found is the promoter of } \\
\text { stress regulated. }\end{array}$ & + & + & + \\
\hline CACATG & $\begin{array}{l}\text { MYC binding site in rd22 gene of Arabidopsis } \\
\text { thaliana; ABA-induction. }\end{array}$ & & + & + \\
\hline CATGTG & $\begin{array}{l}\text { MYC recognition sequence necessary for } \\
\text { expression of erd1 in dehydrated arabidopsis. }\end{array}$ & - & - & + \\
\hline CNGTTR & $\begin{array}{l}\text { ATMYB2 is involved in regulation of genes that are } \\
\text { responsive to water stress in Arabidopsis. }\end{array}$ & + & + & - \\
\hline CCGAC & $\begin{array}{l}\text { Core of low temperature responsive element } \\
\text { (LTRE) of cor } 15 \text { a gene in Arabidopsis. }\end{array}$ & + & + & - \\
\hline TACCGACAT & $\begin{array}{l}\text { Related to responsiveness to drought, low } \\
\text { temperature or high-salt stresses. }\end{array}$ & + & & \\
\hline TAACTG & $\begin{array}{l}\text { AtMYB } 2 \text { is involved in regulation of genes that are } \\
\text { responsive to water stress in Arabidopsis. }\end{array}$ & + & + & + \\
\hline CTAACCA & $\begin{array}{l}\text { Binding site for MYB in dehydration-responsive } \\
\text { gene, } \mathrm{rd} 22 \text {. }\end{array}$ & + & + & + \\
\hline WK[TAGC]CGTR & NAC binding site (NACBS). & + & & + \\
\hline NT CYC1 & $\begin{array}{l}\text { Trichome specific expression of the tobacco } \\
\text { (Nicotiana sylvestris) cembratrien-ol synthase } \\
\text { genes is controlled by both activating and } \\
\text { repressing cis-regions. }\end{array}$ & + & + & \\
\hline
\end{tabular}


Table (3). Cont.

\begin{tabular}{|c|c|c|c|c|}
\hline Ns CBTS-2a & $\begin{array}{l}\text { Trichome specific expression of the snapdragon } \\
\text { (Anthurium majouras). }\end{array}$ & + & - & - \\
\hline Ns CBTS-2b & $\begin{array}{l}\text { Trichome specific expression of the Arabidopsis } \\
\text { (Arabidopsis thaliana). }\end{array}$ & & + & \\
\hline Ns CBTS-3 & $\begin{array}{l}\text { Trichome specific expression of the rice (Oryza } \\
\text { sativa). }\end{array}$ & - & + & + \\
\hline ACACNNG & $\begin{array}{l}\text { Binding core bZIP, ABA response; related to } \\
\text { trichome formation. }\end{array}$ & + & + & + \\
\hline ACACTTG & $\begin{array}{l}\text { Binding core bZIP, ABA response; related to } \\
\text { trichome formation. }\end{array}$ & + & + & + \\
\hline & \multicolumn{4}{|c|}{$\begin{array}{l}\text { Note: The symbol } \mathrm{W} \text { was used in addition to } \mathrm{A} \text { or } \mathrm{T} \text {; the symbol } \mathrm{R} \text { was used in addition to } \mathrm{A} \\
\text { or } \mathrm{G} \text {; the symbol } \mathrm{Y} \text { was used in addition to } \mathrm{C} \text { or } \mathrm{T} \text {; the symbol } \mathrm{K} \text { was used in addition to } \mathrm{G} \text { or } \\
\mathrm{T} \text {; the symbol } \mathrm{W} \text { was used in addition to } \mathrm{T} \text { or } \mathrm{A} \text {; and the symbol } \mathrm{N} \text { was used in additional to } \mathrm{A} \text {, } \\
\mathrm{C}, \mathrm{G} \text { or } \mathrm{T} \text {. }\end{array}$} \\
\hline
\end{tabular}

\section{DISCUSSION}

\section{Solanum Species Show Distinctive Drought Memory Patterns}

Plants that formerly exposed to abiotic stresses may alter their responses to posterior stresses (Barrett and Campbell, 2006; Harb et al., 2010; Ding et al., 2012, 2013, 2014). A recent study of a dryland genotype of Solanum lycopersicum (Summer-set) revealed a memory effect stimulated by drought pre-treatment ( $\mathrm{Li}$ et al., 2019). Water deprivation can strongly induce the water loss in plant leaves (Osakabe et al., 2014). In order to reveal the ability of Solanum species memory, the relative water content was measured as air-drying time extended (0-80 $\mathrm{min})$. The more delayed loss of water, during the equal periods of water-deficiency treatment cycles, might elucidate the increase of the water-retaining ability and it divulged a superior adaptive capability for drought. Stress memory often arises after a plant is exposed to several cycles of that stress. This idea was confirmed by the results of the current study on the relative water content in the leaves of the studied Solanum species after exposure to similar cycles of drought. These results are consistent with several previous studies on Arabidopsis (Ding et al., 2012), aptenia (Fleta-Soriano and Munne-Bosch, 2016) and rice (Li et al., 2019).

\section{Proline and Soluble Sugars Could Contribute to Drought Memory Formation}

It is well known that both of proline and soluble sugars are vital molecules for many biological processes within the plant, including protection from various environmental stresses (Valverde et al., 2004 and Ewas et al., 2017). One of these severe stresses is drought, which causes cell damage. Plants respond to drought stress by increasing the synthesis level of proline and soluble sugars, which in turn can scavenge reactive oxygen species as well

Egyptian J. Desert Res., 69, Special Issue, 69-90 (2019) 
as serving as a molecular chaperone to sustain protein structure (Szabados and Savoure, 2010; Spoljarevic et al., 2011 and Auler et al., 2017). However, biochemical and molecular evidence was lacking in Solanum species concerning whether proline and soluble sugars play crucial functions in shortterm drought memory formation. The impact of exposure to dehydration resulted in the accumulation of proline and soluble sugars in rice and Arabidopsis leaves (Hare and Cress, 1997 and Li et al., 2019). In the present study, levels of proline and soluble sugars were gradually accumulated as drought stress memory cycles increased to prevent the increasing effect of oxidative lipid (Malondialdehyde) in Solanum species. This accumulation was higher in the Solanum wild species leaves including S. nigrum and S. incanum than those of the cultivated species such as $S$. melongena, S. lycopersicum and $S$. tuberosum. This conclusion, in turn, explains the close relationship between the accumulation of these compounds in Solanum species and drought stress memory formation. This evidence is consistent with the results of previous studies by Hanna (2004) and Wu et al. (2014).

\section{Trichome Development Signaling is Involved in Drought Memory Formation}

The results of SEM in the present study confirmed the presence of ten types of trichomes, including glandular and non-glandular trichomes in leaves of the five studied Solanum species. Also, the survey indicated that trichomes density in the leaves of Solanum wild species, including S. nigrum and $S$. incanum is higher than those in cultivated species such as S. lycopersicum and $S$. tuberosum. Previous studies have confirmed a significant increase in trichome density in the leaves of dry and desert plants more than those of the relative cultivated species such as pepper (Kim et al., 2012), tomato (GaldonArmero et al., 2018) and rice (Li et al., 2019). These results are consistent with the results of proline and soluble sugars accumulation after exposure to drought stress in the same Solanum species. The results of the bioinformatics analysis also confirmed the abundance of cis-regulatory elements responsive to drought stress in the promoter regions of MIXTA, MIXTA-likel and MIXTAlike2, referring to the close relationship between these genes and drought stress tolerance. Furthermore, induction in the expression level of MIXTA, MIXTA-like1 and MIXTA-like2 "the key genes of trichomes formation" after different drought stress treatments suggest the cross-talk between trichomes and stress memory formation in Solanum species. Interestingly, the transcription level of these genes was significantly higher in the leaves of wild species including $S$. nigrum and $S$. incanum, followed by $S$. melongena than those of cultivated species such as $S$. lycopersicum and $S$. tuberosum. The induction in transcription level of MIXTA genes under drought stress condition was also reported in other plant species, including AmMIXTA1 from Antirrhinum majus, PhMIXTA1 of Petunia hybrida, AtMIXTA16, AtMIXTA17, AtMIXTA106 in Arabidopsis thaliana, GhMIXTA25, GhMIXTA25-like in 
Gossypium hirsuta, DcMIXTA1 from Dendrobium crumenatum, MtMIXTA3 of Medicago truncatula and SIMIXI from Solanum lycopersicum (PerezRodriguez et al., 2005; Baumann et al. 2007; Gilding and Marks, 2010; Pastore et al., 2011; Machado et al., 2009; Walford et al., 2011 and Ewas et al., 2016), respectively. These findings indicate the role of trichomes in drought stress tolerance in Solanum species. The idea of stress memory is associated with trichome density was confirmed previously in several desert species, including Achillea fragrantissima, Seriphidiom herba-alba, Artemisia judaica, Launaea spinosa, Heliotropium arbainense, Moltkiopsis ciliata, Zilla spinosa, Cleome droserifolia, Convolvulus lanatus, Chrozophora obliqua, Acacia tortilis subsp. raddiana, Astragalus spinosus, Crotalaria aegyptiaca, Salvia deserti, Teucrium pilosum and Ochradenus baccatus, Lycium shawii Roem and Fagonia arabica (Gamal, 1997).

\section{CONCLUSION}

This study provides a deep insight into drought stress memory formation in the studied Solanum species, which can be summarized by the presence of three distinctive mechanisms related to trichomes density in these species. The first is a physiological mechanism responsible for increasing trichomes density and this, in turn, reflects the sunlight and reduces the relative water loss by controlling stomatal closure. The second is a biochemical mechanism within the trichomes of these species. The current study reveals that trichomes of Solanum species are a prolific source of a vast number of metabolites. These metabolites are generated within the glandular and non-glandular trichomes by essential enzymes required in the biosynthesis of proline, soluble sugars, flavonoids and terpenoids. Regulation of the biosynthetic genes of these metabolites and key genes of trichome formation are associated with drought stress memory and this is the third mechanism (Johansen, 1940; Kaur and Goel, 2011; Pattanaik et al., 2014 and Ewas et al., 2016). This report shed light into endemism of Solanum species in their defined zones.

\section{ACKNOWLEDGMENT}

The authors would like to thank Prof. Ye Zhibiao and Prof. Conghua Xie for their technical support to the research; Dr. Eman Khames for advice and suggestions. The authors also extend their gratitude to Tanta University and Alexandria University, Egypt, for providing the opportunity to pursue this study.

Table (S1). Primer pairs used in this study for gene detection and expression analysis.

Egyptian J. Desert Res., 69, Special Issue, 69-90 (2019) 


\begin{tabular}{ccc}
\hline Experiment & Primer name & Primer Sequence \\
\hline \multirow{5}{*}{ Gene detection } & MIXTA-FW & TTCAGTCGACATGGGTCGATCTCCGTGT \\
& MIXTA-RV & TGGTCTAGAGGTCAGGCTTTCAGCACG \\
& MIXTA-likel-FW & GGTAGTATTTGAGAAACTGGGCTCTCT \\
& MIXTA-likel-RV & ATATCTCGAGGCCGACCACCTATTCCC \\
& MIXTA-like2-FW & ATGGATTCTTTCTCTACTTCTTCACTTT \\
& MIXTA-like2-RV & TTACATTCTTGGTTAATTTTAGCTCTT \\
\hline \multirow{5}{*}{ Expression analysis } & MIXTA-FW & GCGAGCGCTAGTGCTGGTAT \\
& MIXTA-RV & TAATATGTTGCGCATTTTCGAAA \\
& MIXTA-likel-FW & TTTCATTTTCACAATTTCCGCC \\
& MIXTA-likel-RV & CTGGAGGTCCGGGAGGTAG \\
& MIXTA-like2-FW & TTAAAGGGTCCACGTGTTTGG \\
& MIXTA-like2-RV & CACGCGCGGAGATTATCTACT \\
\hline
\end{tabular}

\section{REFERENCES}

Ager, F.J., M.D.Ynsa, J.R. Domnguez-Sol, M.C. Lopez-Mart, C. Gotorand and L.C. Romer (2003). Nuclear micro-probe analysis of Arabidopsis thaliana leaves. Nucl. Instr. Methods. Phys. Res., 210: 401-406.

Auler, P.A., M.N.D. Amaral, G.D.S. Rodrigues, L.C. Benitez, L.C.D. Maia, G.M. Souza et al. (2017). Molecular responses to recurrent drought in two contrasting rice genotypes. Planta, 246: 899-914.

Barrett, J. and C. Campbell (2006). S-ABA: Developing a new tool for the big grower. Big Grower, 1: 26-29.

Bates, L.S., R.P. Waldren and I.D. Teare (1973). Rapid determination of free proline for water studies. Plant Soil, 39: 205-207.

Baumann, K., M. Perez-Rodriguez, D. Bradley, J. Venail, P. Bailey, H. Jin, R. Koes, K. Roberts and C. Martin (2007). Development, 134: 16911701.

D'Arcy, W.G. (1972). Solanaceae studies II: Typification of subdivisions of Solanum. Ann. Missouri Bot. Gard., 59: 262-278.

D'Arcy, W.G. (1991). The Solanaceae Since 1976, with A Review of its Biogeography. In: 'Solanaceae III: Taxonomy, Chemistry, Evolution' Hawkes, J.G., R.N. Lester, M. Nee and N. Estrada (Eds.). Royal Botanic Gardens, Kew, pp. 75-137.

Dhawan, S.S., P. Shukla, P. Gupta and R.K. Lal (2016). A cold-tolerant evergreen interspecific hybrid of Ocimum kilimandscharicum and Ocimum basilicum: analyzing trichomes and molecular variations. Protoplasma, 3: 845-855.

Ding, Y., M. Fromm and Z. Avramova (2012). Multiple exposures to drought 'train' transcriptional responses in Arabidopsis. Nat. Commun., 3: 740. 
Ding, H., Z. Zhang, L.X. Dai, W.W. Song, T. Kang and C. Dunwei (2013). Responses of root morphology of peanut varieties differing in drought tolerance to water-deficient stress. Acta Ecologica Sinica, 33 (17): 5169-5176.

Ding, L., Y.R. Li, Y. Li, Q.R. Shen amd S.W. Guo (2014). Effects of drought stress on photosynthesis and water status of rice leaves. Chin. J. Rice Sci., 28 (1): 65-70.

Dudareva, N., N. Andersson, I. Orlova, N. Gatto, M. Reichelt, D. Rhodes, W. Boland and J. Gershenzon (2005). The nonmevalonate pathway supports both monoterpene and sesquiterpene formation in snapdragon flowers. PNAS, 102 (3): 933-938.

Espigares, T. and B. Peco (1995). Mediterranean annual pasture dynamics: impact of autumn drought. J. Ecol., 83: 135-142.

Ewas, M., Y. Gao, S. Wang, X. Liu, H. Zhang, E.M.E. Nishawy, F. Ali, R. Shahzad, K. Ziaf, H. Subthain, C. Martin and J. Luo (2016). Manipulation of $S I M X l$ for enhanced carotenoids accumulation and drought resistance in tomato. Sci. Bull. (Beijing), 61: 1413-1418.

Ewas, M., Y.Q. Gao, F. Ali, E.M. Nishawy, R. Shahzad, H. Subthain, M. Amar, C. Martin and J. Luo (2017). RNA-seq reveals mechanisms of SlMX1 for enhanced carotenoids and terpenoids accumulation along with stress resistance in tomato. Sci. Bull. (Beijing), 62: 476-485.

Fleta-Soriano, E. and S. Munne-Bosch (2016). Stress memory and the inevitable effects of drought: a physiological perspective. Front. Plant Sci., 7: 143.

Frary, A., S. Doganlar and M.C. Daunay (2003). Eggplant. In: "Genome Mapping and Molecular Breeding in Plants, 5". Kole, C. (ed.) Vegetables. Springer, Berlin, Heidelberg.

Galdon-Armero, J., M. Fullana-Pericas, P.A. Mulet, M.A. Conesa, C. Martin and J. Galmes (2018). The ratio of trichomes to stomata is associated with water use efficiency in Solanum lycopersicum (tomato). Plant J., 96 (3): 607-619.

Gamal, M.F. (1997). Leaf anatomy and its relation to the ecophysiology of some non-succulent desert plants from Egypt. J. Arid Environ., 36: 499-525.

Gilding, E.K. and M.D. Marks (2010). Analysis of purified glabra3shapeshifter trichomes reveals a role for NOECK in regulating early trichome morphogenic events. Plant J., 64: 304-317.

Glover, B.J. and C. Martin (2000). Speciation of Epidermal Cell Morphology. In: 'Advances in Botanical Research'. Plant Trichomes, Hallahan, D.L., J.C. Gray and J.A. Callow (Eds.). Academic Press, New York, pp. 193-217.

Hanna, B. (2004). Free proline accumulation in leaves of cultivated plant species under water deficit conditions. Acta Agrobotonica, 57: 57-67.

Egyptian J. Desert Res., 69, Special Issue, 69-90 (2019) 
Harb, A., A. Krishnan, M.M. Ambavaram and A. Pereira (2010). Molecular and physiological analysis of drought stress in Arabidopsis reveals early responses leading to acclimation in plant growth. Plant Physiol., 154 (3): 1254-1271.

Hare, P.D. and W.A. Cress (1997). Metabolic implications of stress-induced proline accumulation in plants. Plant Growth Regul., 21: 79-102.

Johansen, D.A. (1940). In: 'Plant Microtechnique'. McGraw-Hill, New York.

Kang, J.H., F. Shi, A.D. Jones, M.D. Marks and G.A. Howe (2010). Distortion of trichome morphology by the hairless mutation of tomato affects leaf surface chemistry. J. Exp. Bot., 61: 1053-1064.

Kaur, M. and R.K. Goel (2011). Anti-Convulsant Activity of Boerhaavia diffusa: Plausible Role of Calcium Channel Antagonism. EvidenceBased Complementary and Alternative Medicine, Article ID 310420 .

Kim, S., Y.P. Wairkar, R.W. Daniels and A. Diantonio (2010). The novel endosomal membrane protein Ema interacts with the class C VpsHOPS complex to promote endosomal maturation. J. Cell Biol., 188 (5): 717-734.

Kim, H.J., J.H. Han, S. Kim, H.R. Lee, J.S. Shin, J.H. Kim, J. Cho, Y.H. Kim, H.J. Lee, B.D. Kim and D. Choi (2011). Trichome density of main stem is tightly linked to PepMoV resistance in chili pepper (Capsicum annuum L.). Theor. Appl. Genet., 122: 1051-1058.

Kim, H., E. Seo, J. Kim, H. Cheong, B. Kang and D. Choi (2012) Morphological classification of trichomes associated with possible biotic stress resistance in the genus Capsicum. Plant Pathol. J., 28 (1): 107-113.

Levin, D.A. (1973). The role of trichomes in plant defense. Q. Rev. Biol., 48: 3-15.

Li, P., H. Yang, L. Wang et al. (2019). Physiological and transcriptome analyses reveal short-term responses and formation of memory under drought stress in rice. Front. Genet., 10: 55.

Luckwill, L.C. (1943). In: 'The Genus Lycopersicon: An Historical, Biological, and Taxonomic Survey of the Wild and Cultivated Tomatoes'. Aberdeen University Press, Aberdeen, $44 \mathrm{p}$.

Machado, G., S.R. Gustavo and A.B. Bruno (2009). Comportamento reprodutivo de opiliões (arachnida): sistemas de acasalamento e cuidado parental. Oecol. Bras., 13 (1): 58-79.

Noda, K., B.J. Glover, P. Linstead et al. (1994). Flower colour intensity depends on specialized cell shape controlled by a Myb related transcription factor. Nature, 369: 661-664.

Oh, H.W., J.M. Campusano, L.G.W. Hilgenberg, X. Sun, M.A. Smith and D.K. O'Dowd (2008). Ultrastructural analysis of chemical synapses and gap junctions between Drosophila brain neurons in culture. Dev. Neurobiol., 68(3): 281-294. 
Orozco C.M. and C.A. Ryan (1999). Hydrogen peroxide is generated systemically in plant leaves by wounding and systemin via the octadecanoid pathway. PNAS, 96 (11): 6553-6557.

Osakabe, Y., K. Osakabe, K. Shinozaki and L.S.P. Tran (2014). Response of plants to water stress. Front. Plant Sci., 5: 86.

Oshima, Y., M. Shikata, T. Koyama et al. (2013). MIXTA-like transcription factors and WAX INDUCER1/SHINE1 coordinately regulate cuticle development in Arabidopsis and Torenia fournieri. Plant Cell, 25: 1609-1624.

Pastore, J.J., A. Limpuangthip, N. Yamaguchi, M.F. Wu, Y. Sang, S.K. Han, L. Malaspina, N. Chavdaroff, A. Yamaguchi and D. Wagner (2011). LATE MERISTEM IDENTITY2 acts together with LEAFY to activate APETALA1. Development, 138 (15): 3189-3198.

Pattanaik, S., B. Patra, S.K. Singh and L. Yuan (2014). Anover view of the gene regulatory network controlling trichome development in the model plant, Arabidopsis. Front. Plant Sci., 5: 259.

Perez-Rodriguez, M., F.W. Jaffe, E. Butelli, B.J. Glover and C. Martin (2005). Development of three different cell types is associated with the activity of a specific MYB transcription factor in the ventral petal of Antirrhinum majus flowers. Development, 132: 359 -370.

Plaisted, D.A., G.D. Alexander, H. Chu and S.J. Lee (1992). Conditional term rewriting and first-order theorem proving. In Proceedings of the Third International Workshop on Conditional Term-Rewriting Systems, Pont-a-Mousson, France.

Qian, B., X. Li, X. Liu, P. Chen, C. Ren and C. Dai (2015). Enhanced drought tolerance in transgenic rice overexpressing of maize $\mathrm{C} 4$ phosphoenolpyruvate carboxylase gene via $\mathrm{NO}$ and $\mathrm{Ca} 2 \mathrm{C}^{+}$. J. Plant Physiol., 175: 9-20.

Schilmiller, A.L., R.L. Last and E. Pichersky (2008). Harnessing plant trichome biochemistry for the production of useful compounds. Plant J., 54: 702-711.

Schmittgen, T.D. and K.L. Livak (2008). Analyzing real-time PCR data by the comparative C(T) method. Nature Prot., 3: 1101-1108.

Skaltsa, H., E. Verykokidou, C. Harvala, G. Karabourniotis and Y. Manetasi (1994). UV-B protective potential and flavonoid content of leaf hairs of Quercus ilex. Phytochemistry, 37: 987-990.

Spoljarevic, M., D. Agic, M. Lisjak, A. Gumze, I.D. Wilson, J.T. Hancock and T. Teklic (2011). The relationship of proline content and metabolism on the productivity of maize plants. Plant Signal. Behav., 6 (2): 251-257.

Szabados, L. and A. Savoure (2010). Proline: a multifunctional amino acid. Trends Plant Sci., 15: 89-97.

Theobald, W.L., J.L. Krahulik and R.C. Rollins (1979). Trichome description and classification. In: 'Anatomy of the Dicotyledons', $2^{\text {nd }}$ edition,

Egyptian J. Desert Res., 69, Special Issue, 69-90 (2019) 
Metcalfe, C.R. and L. Chalk (Eds.), Clarendon Press, Oxford, pp. 4053.

Thomas, J.G., D.C. Catherine and N.S. John (1992). Temperature and photoperiod influence trichome density and sesquiterpene content of Lycopersicon hirsutum f. hirsutum ${ }^{1}$. Plant Physiol., 100: 1403- 1405.

Valverde, F., A. Mouradov, W. Soppe, D. Ravenscroft, A. Samach and G. Coupland (2004). Photoreceptor regulation of CONSTANS protein in photoperiodic flowering. Science, 303: 1003-1006.

Walford, S.A., Y. Wu, D.J. Llewellyn and E.S. Dennis (2011). GhMYB25like: a key regulator of early cotton fibre development. Plant J., 65: 785-797.

Wu, G., Z. Zhou, P. Chen, X. Tang, H. Shao and H. Wang (2014). Comparative ecophysiological study of salt stress for wild and cultivated soybean species from the Yellow River Delta, China. Scientific World J., Article ID 651745.

Yang, C., H. Li, J. Zhang, Z. Luo, P. Gong, C. Zhang, J. Li, T. Wang, Y. Zhang, Y. Lu and Z. Ye (2011). A regulatory gene induces trichome formation and embryo lethality in tomato. Proc. Natl. Acad. Sci. USA, 108: 11836-11841.

Yeom, S.I., E. Seo, S.K. Oh, K.W. Kim and D. Choi (2011). A common plant cell-wall protein HyPRP1 has dual roles as a positive regulator of cell death and a negative regulator of basal defense against pathogens. Plant J., 69 (5): 755-768.

Yoon, H.S, J.D. Hackett, C. Ciniglia, G. Pinto and D. Bhattacharya (2008). A molecular time line for the origin of photosynthetic eukaryotes. Mol. Biol. Evol., 21(5): 809-818. 


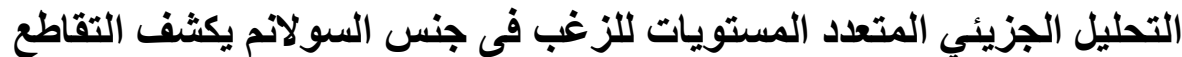

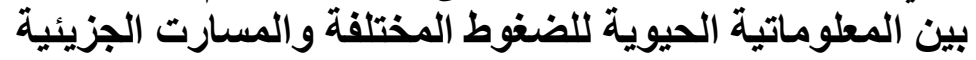 للمقاومة
}

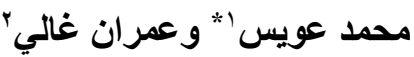

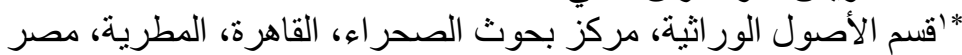

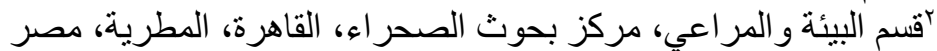

يعد الزغب في النبات تر اكيب بيولوجية فريدة تنشأ من السطح العلوي للبشرة كما أنها تمثل

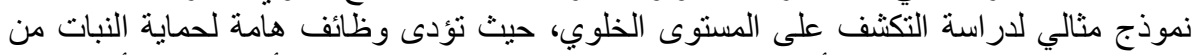

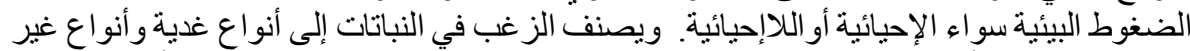

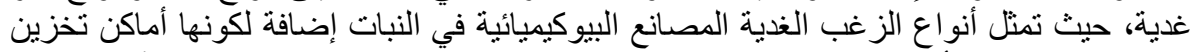

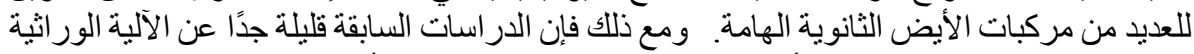

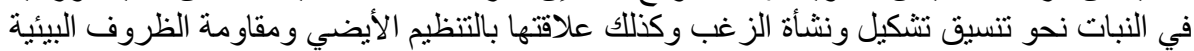

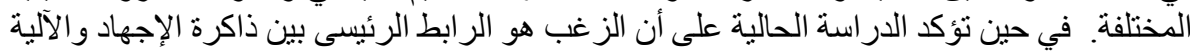

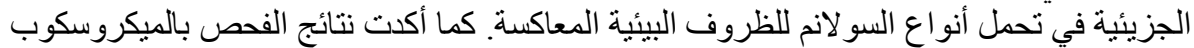

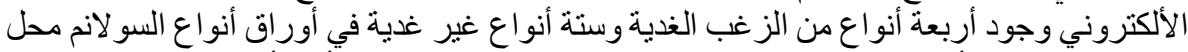

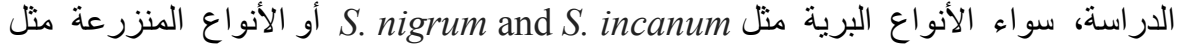
(S. lycopersicum, S. tuberosum and S. melongena

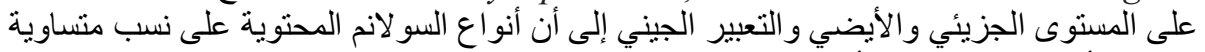

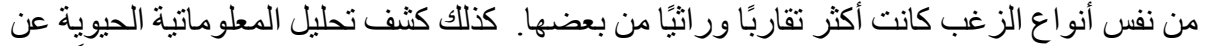

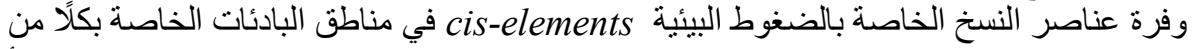
جينات MIXTA, MIXTA-like1 and MIXTA-like2 وهي الجينات المسئولة عن تشكيل ونشأة

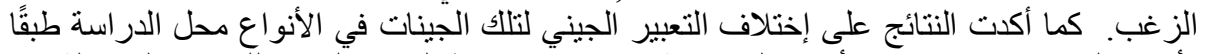

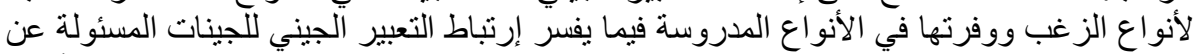

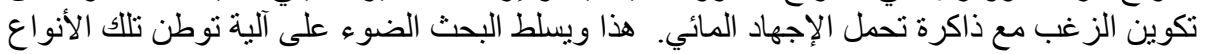
محل الدراسة في مناطقها البيئية المحددة.

Egyptian J. Desert Res., 69, Special Issue, 69-90 (2019) 